\title{
Application of clay-rich full plant tailings paste backfill technology
}

\author{
AX Wu University of Science and Technology Beijing, China \\ J Wang University of Science and Technology Beijing, China \\ S Wang University of Science and Technology Beijing, China \\ X Yang Jiashi Tonghui Copper Mine Co., Ltd, China \\ F Zhou Jiashi Tonghui Copper Mine Co., Ltd, China
}

\begin{abstract}
Jiashi Tonghui Copper Mine (JTCM) is located in Kashgar District, Sinkiang, China. In the presence of water, the ore and rock of this copper mine are easy to slime. In this situation, paste backfill with the advantage of no bleeding has become the required filling method. However, the content of magnesium silicate clay minerals in the unclassified tailings reaches $72.28 \%$, which is two to seven times more than other mines. Paste backfill application in this mine was faced with three technical problems: (i) slow settling and difficulties with thickening, (ii) low strength and large consumption of cement, and (iii) high yield stress and difficulties with transport.

This paper introduces several solutions to the above problems. Firstly, a suitable flocculant which matches mineral properties was selected and a secondary flocculant dilution system was added to improve the settling rate of clay-rich unclassified tailings. Thus, an underflow concentration of 70-72\% can be achieved. Secondly, Gobi aggregates were added to optimise slurry gradation. By this means, paste concentration increased from 75-80\% and the strength increased by five times. Thirdly, adding pumping admixtures can reduce the yield stress of high-concentration slurry by $45 \%$ and decrease the plastic viscosity by two times. The paste slurry was transported over a distance of $2.6 \mathrm{~km}$ by a high-pressure (15 MPa) plunger pump. Based on this, long-distance transportation of paste with high clay content and high viscosity can be achieved.
\end{abstract}

Keywords: clay-rich full plant tailings, paste backfill, gradation optimisation, long-distance transportation

\section{Introduction}

Jiashi Tonghui Copper Mine (JTCM), with a 14 year mining history, is located in Kashgar District, Sinkiang, western China. JTCM is the largest copper mine in southern Sinkiang with an annual production capacity of $700,000 \mathrm{t}$. Pillarless shrinkage stoping with shallow holes was adopted at JTCM and a large number of untreated mined-out areas have been left. With the exploitation of deep resources, several problems are emerging.

- The mined-out areas were connected with the surface. Until now, five surface-collapsed areas have been found. The mountain torrents can easily enter the caving area and underground space due to the uncovered land surface, which could result in a serious threat to personnel, equipment and the whole production system.

- A large reserve of underground aquifers is hidden near the orebody. The surface-collapsed areas may lead to the risk of water inflow when developing and preparing deep resources.

- With the increase of underground mined-out areas, stope collapses occurred frequently under the effect of ground stress, which contributed to the reduction of mining capacity and economic benefits, and threatened production safety.

- The ore and rock of this mine are weak and low in strength $(f<3)$. In particular, they are easy to slime in the presence of water. 
- The service life of the tailings dam is not long. It has accumulated about 1.5 $\mathrm{Mt}$ of tailings with an increasing rate of $600,000 \mathrm{t}$ per year.

Therefore, a filling method should be adopted to control the ground pressure to avoid stope collapse and surface subsidence. Traditional filling methods, especially low-concentration filling methods, cannot be applied to this mine due to the weak argillaceous rock. Hence, paste backfill is imperative. However, the high clay content of unclassified tailings will lead to several problems such as slow settling and difficulties with thickening, low strength, high yield stress and transport problems.

To solve these problems, clay-rich full plant tailings paste backfill technology was studied. The paste backfill system at JTCM is introduced in this paper.

\section{Paste backfill system}

The paste backfill system at JTCM, after two years of construction, was put into operation in July 2014. As shown in Figure 1(a), it consists of a tailings thickening system, the aggregate-cement-pumping admixture adding system, the mixing system and the pumping system. Its annual filling capacity is about $400,000 \mathrm{~m}^{3}$. Other key indicators are as follows:

- Handling capacity of thickener: $100 \mathrm{t} / \mathrm{hr}$ (for dry tailings).

- Underflow concentration: 70-72\%.

- Paste concentration: $78-80 \%$.

- Capacity of paste backfill system: $90 \mathrm{~m}^{3} / \mathrm{hr}$, annual filling capacity: $400,000 \mathrm{~m}^{3}$.

- Unit consumption of cement: $90 \mathrm{~kg} / \mathrm{m}^{3}$ for stope and $219 \mathrm{~kg} / \mathrm{m}^{3}$ for artificial roof.

- Twenty-eight day strength of filling body: 1.2 MPa for stope and 4-5 MPa for artificial roof.

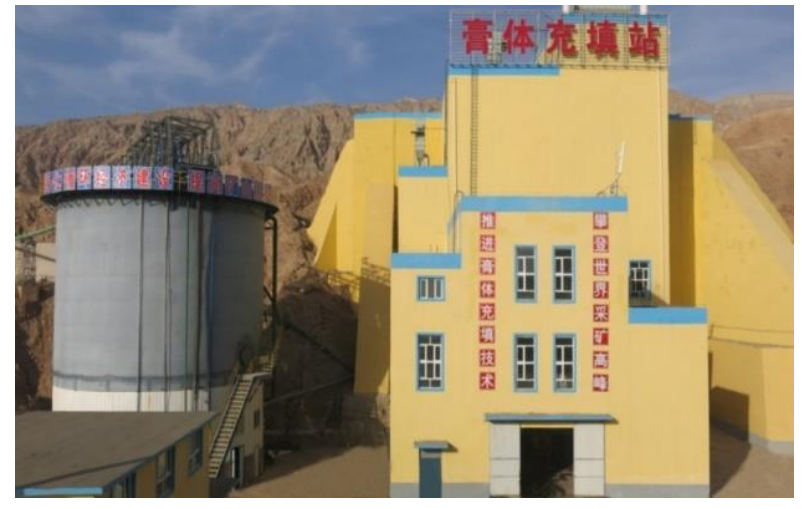

(a)

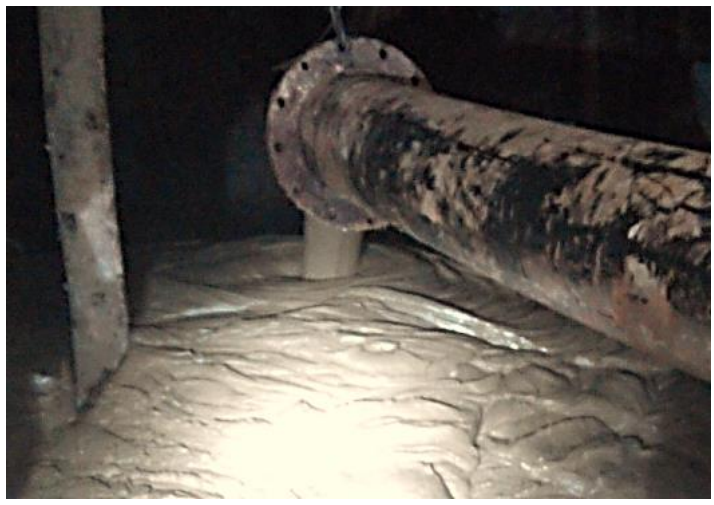

(b)

Figure 1 Photographs of JTCM; (a) Paste backfill plant; and, (b) Paste being transported to stope

The flowchart of the paste backfill system is shown in Figure 2 . The slurry from the process plant, with a concentration of $25-30 \%$, is thickened by a deep cone thickener (diameter of $14 \mathrm{~m}$ and height of $20 \mathrm{~m}$ ). Next, the underflow, with a concentration of $70-72 \%$, is transported to the two-stage double screw horizontal mixer and is mixed with cement, pumping admixture and coarse aggregates to prepare paste with a concentration of $78-80 \%$. Finally, paste slurry is pumped into the underground stope by plunger pump (Figure 1(b)).

The programmable logic controller (PLC) automatic control system is also an important part of this paste backfill system. All equipment and valves can be operated by computers in the control room, which is highly automated and greatly reduces the number of onsite operators. It can also enable the precise addition of materials and stable control of paste concentration. 


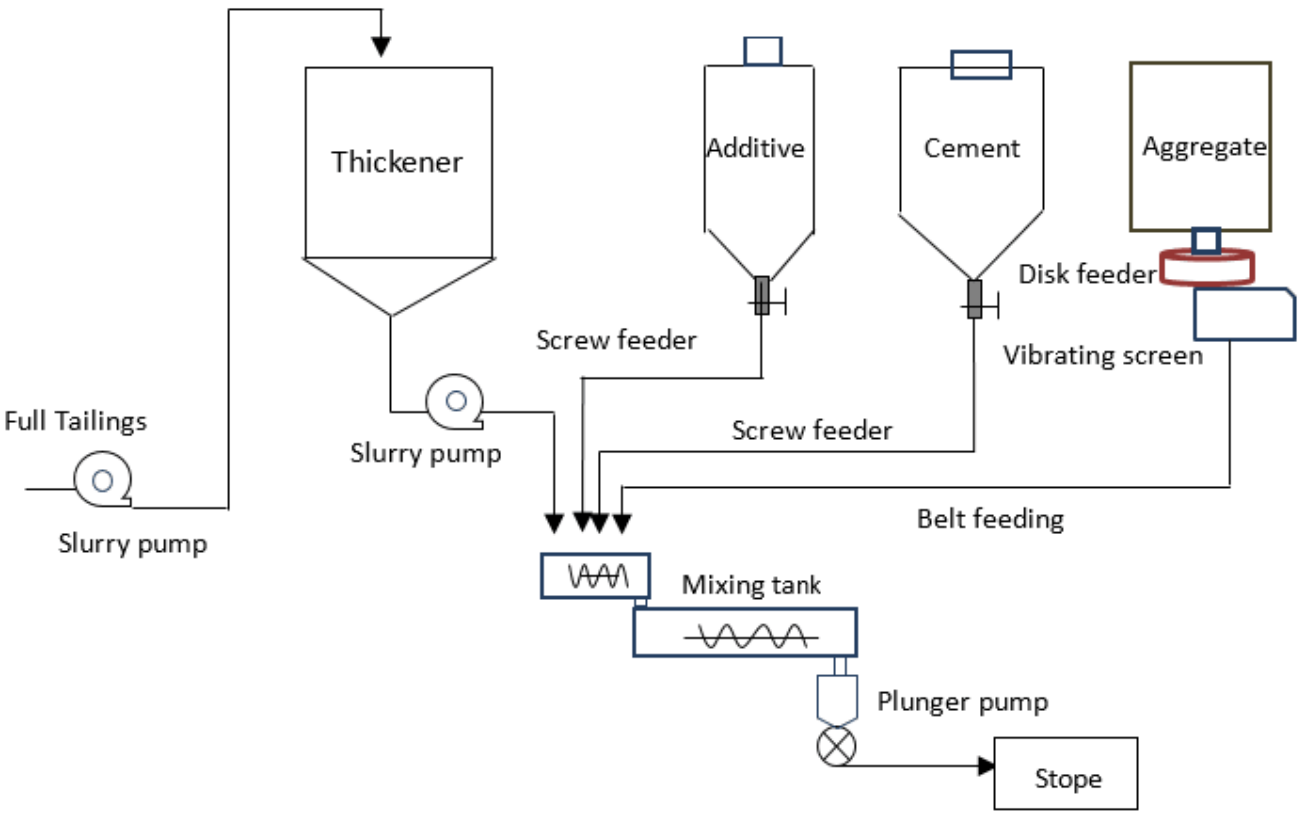

Figure 2 Flowchart of the JTCM paste backfill system

\section{$3 \quad$ Challenges and current practices}

\section{$3.1 \quad$ Thickening}

\subsubsection{Challenges for thickening}

The X-ray diffraction (XRD) analysis of the unclassified tailings (Figure 3) at JTCM was carried out. As shown in Figure 4, the content of magnesium silicate and aluminium silicate, which form the main components of clay minerals, reaches about $10 \%$. Due to this, the unclassified tailings in JTCM have colloidal properties, which contributes to higher yield stress and viscosity when reacting with water.

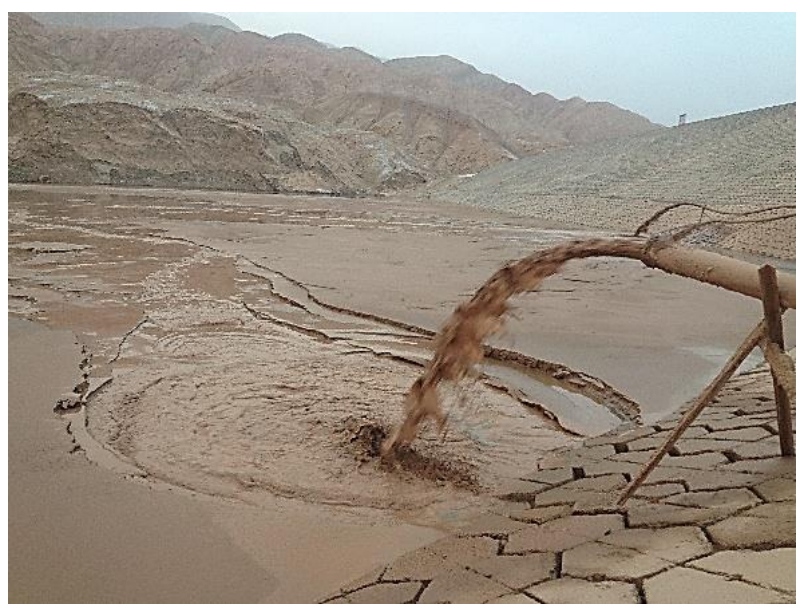

Figure 3 Discharge of clay-rich full plant tailings 


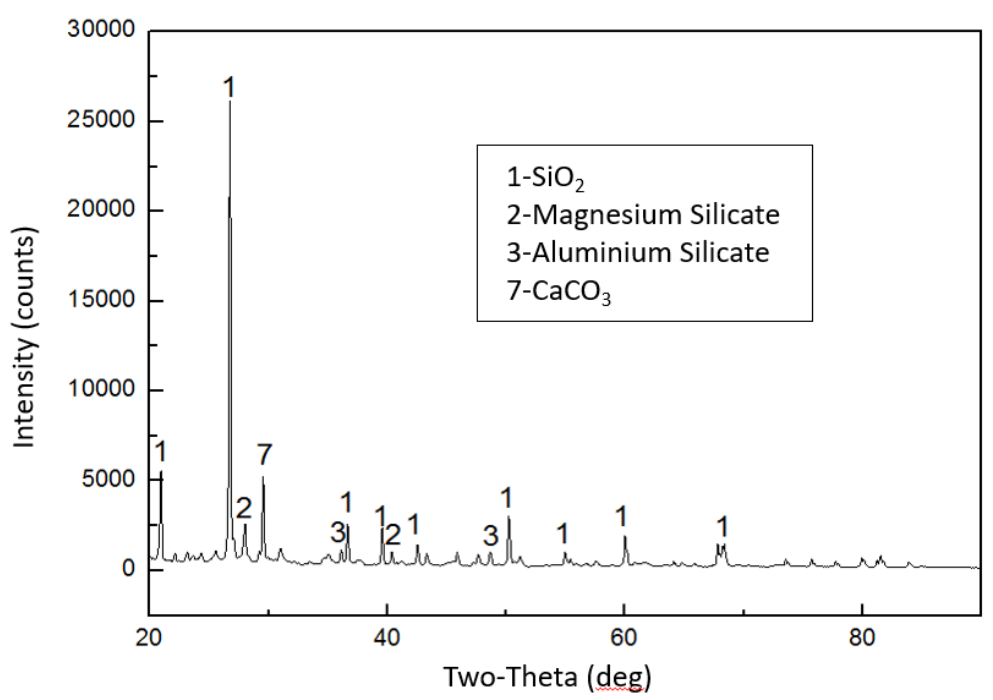

Figure 4 X-ray diffraction pattern of the JTCM full plant tailings

The grading curves (Figure 5) of the unclassified tailings at JTCM, detected by a laser particle size analyser, show that the $-20 \mu \mathrm{m}$ particle content of the unclassified tailings is $29.8 \%$ and the $-74 \mu \mathrm{m}$ particle content is $64.32 \%$. Due to a large amount of ultrafine particles and clay minerals, flocculants cannot play a good role in gathering single particles. As fewer bigger flocs are formed in the slurry, the settling velocity of flocs is $10 \mathrm{~m} / \mathrm{hr}$, which is smaller than the overflow velocity, resulting in turbid overflow water in the thickener (Figure 6).

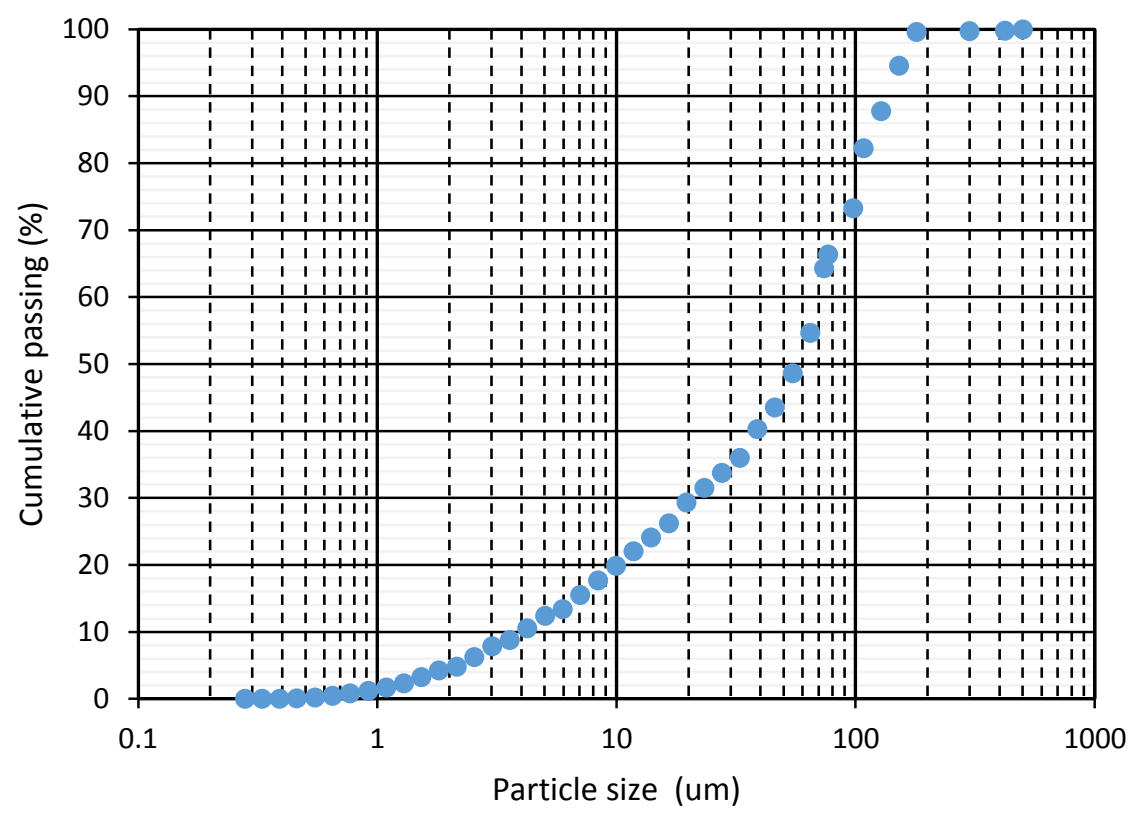

Figure 5 Particle size distribution of full plant tailings in JTCM 


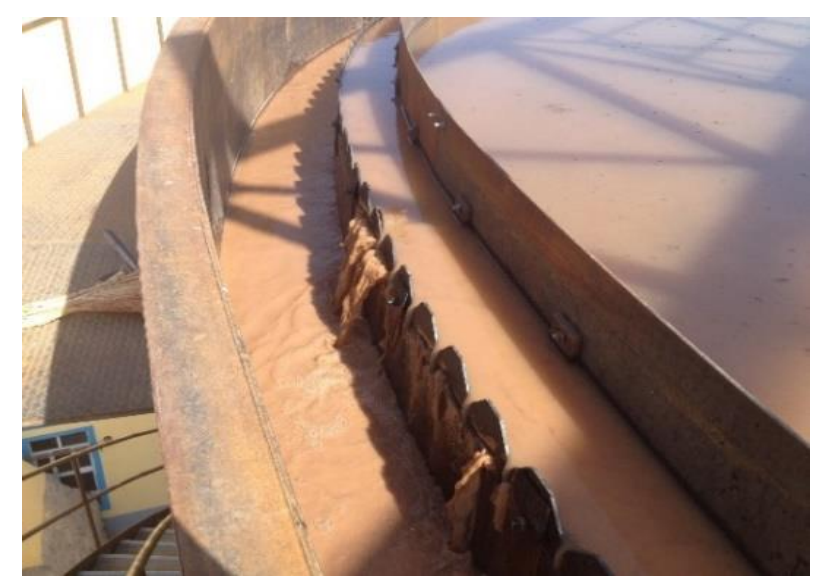

Figure 6 Turbid overflow water in the thickener

\subsubsection{Measures and effects}

Two major improvement measures were proposed:

1. Selecting the most appropriate flocculant.

2. Improving the mixing effect of flocculant and unclassified tailings.

Sedimentation tests with different types of flocculants were carried out. Taking settling velocity as criteria, the test results indicated that the MF5250 flocculant was obviously superior to other flocculants. The effect of MF5250 flocculant on properties such as settling velocity, mud height and overflow clarity can achieve the desired results (Table 1). The following conclusions were obtained from industrial experiments.

- When the feed rate is $110-120 \mathrm{~m}^{3} / \mathrm{hr}$, the unit consumption of flocculant is $20-25 \mathrm{~g} / \mathrm{t}$.

- When the feed rate is $170-180 \mathrm{~m}^{3} / \mathrm{hr}$, the unit consumption of flocculant is $28-30 \mathrm{~g} / \mathrm{t}$.

Table 1 Use effect of MF5250 flocculant

\begin{tabular}{llll}
\hline Number & Index & Unit consumption of $\mathbf{2 0} \mathbf{~ g / t}$ & Unit consumption of $\mathbf{3 5} \mathbf{~ g / t}$ \\
\hline 1 & Settling time $(\mathrm{sec})(450-400 \mathrm{ml})$ & 15.64 & 7.26 \\
2 & Settling velocity $(\mathrm{m} / \mathrm{hr})$ & 12.89 & 27.77 \\
3 & Mud height after two mins $(\mathrm{mm})$ & 170 & 170 \\
4 & Overflow clarity & 37 & 38 \\
\hline
\end{tabular}

On the other hand, as high-concentration, small-flow flocculants result in a slow reaction rate, a secondary dilution system was self-developed (Figure 7). Overflow water was added to the feeding pipe by the water pump installed on the top of thickener so that the flocculant concentration could be reduced from 0.05 to $0.007 \%$, and the dilution effect of slurry in the well could be greatly improved. A low-concentration, high-flow mixing enhancement mode can result from this method, which will enhance the mixing effect of flocculant and tailings particles. 


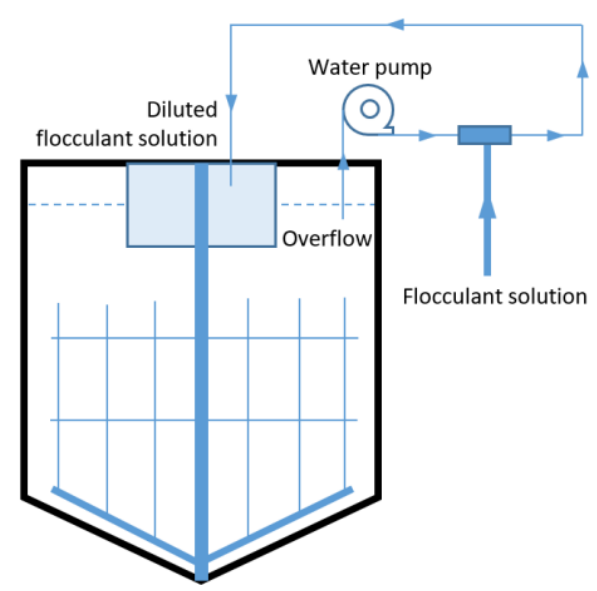

(a)

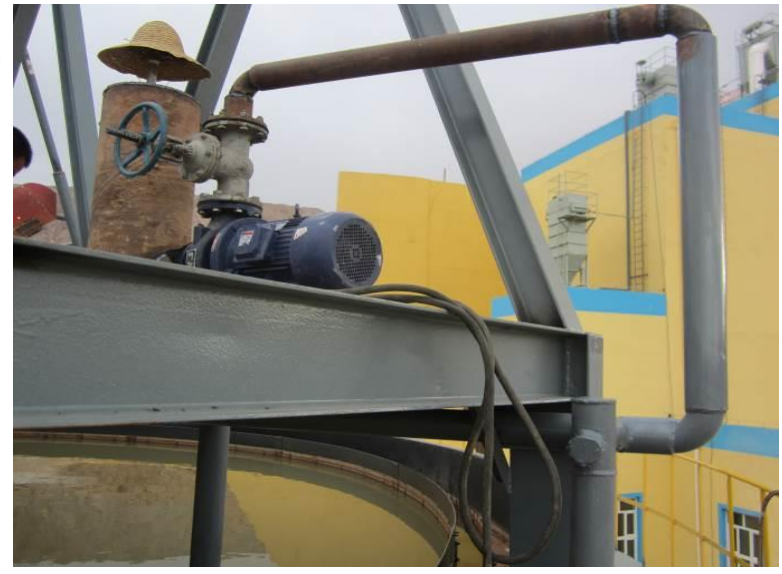

(b)

Figure 7 Secondary dilution system of flocculants; (a) Schematic diagram; and, (b) Photograph

By taking the aforementioned measures, the unit consumption of flocculant was reduced from 35 to $20 \mathrm{~g} / \mathrm{t}$ and the flocculation effect was improved. The solids content of overflow water was reduced to less than $200 \mathrm{ppm}$ (Figure 8). Furthermore, the return water from the thickener can be reused at the workshop and process plant, which helps achieve effective usage of $70 \%$ of the water and greatly reduces water consumption and cost.

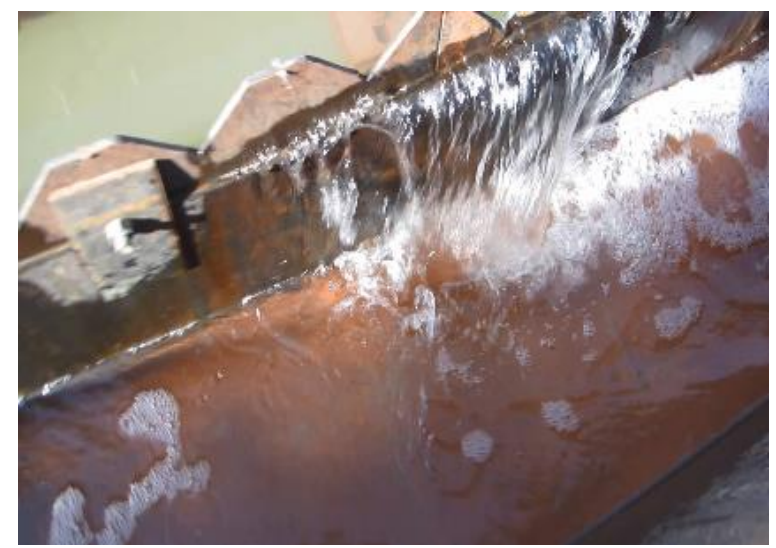

Figure 8 Clear overflow water

\subsection{Pumping}

\subsubsection{Challenges with pumping}

Some related parameters of paste slurry in JTCM are as follows:

- Weight concentration: $78 \%$.

- Yield stress: $320 \mathrm{~Pa}$.

- Plastic viscosity: $0.4197 \mathrm{~Pa} \cdot \mathrm{s}$.

Some relevant parameters of the pipeline system at JTCM are as follows:

- Longest conveying distance (Figure 9): 2,599 m.

- Multiple-ratio pipe length-to-column in filling: 7.1.

- Friction resistance: $57.5 \mathrm{MPa}$.

Based on these parameters, if using the plunger pump with a rated pump pressure of $15 \mathrm{MPa}$, four such plunger pumps will be needed to transport paste slurry to the stope. 


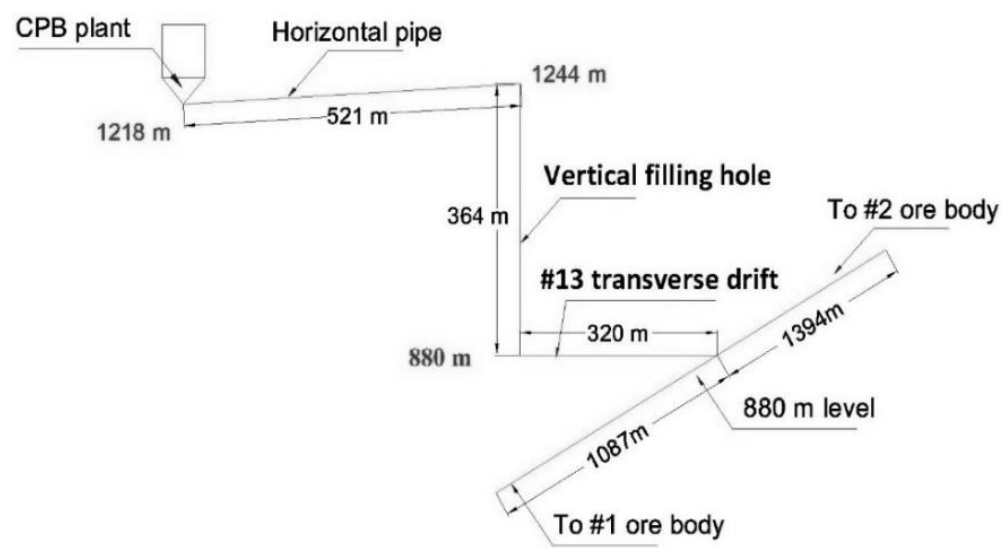

Figure 9 Pipeline layout

\subsubsection{Measures and effects}

As shown in Figure 10, pumping admixtures can improve the fluidity of clay-rich paste slurry. As Figure 11 shows, if adding pumping admixture with an addition rate of $8 \%$ of the cement addition rate at a slurry concentration of $78 \%$, the yield stress of paste slurry can be reduced from $320 \mathrm{~Pa}$ to about $175 \mathrm{~Pa}-$ a decrease of $45 \%$.

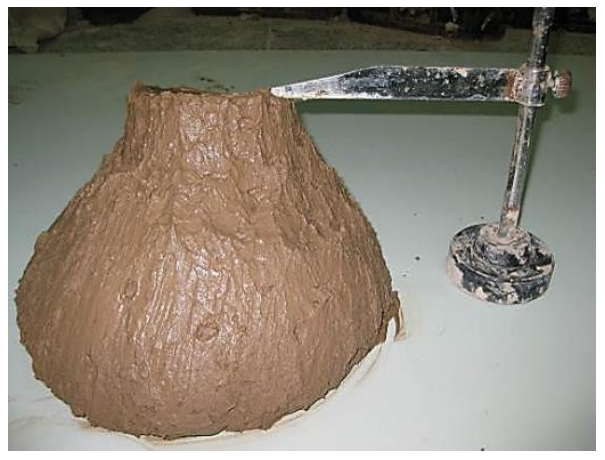

(a)

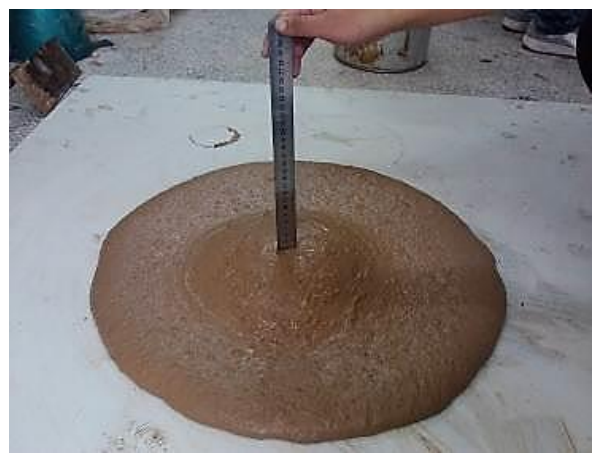

(b)

Figure 10 Effect of adding pumping admixture on slump; (a) Slump $=5 \mathrm{~cm}, \mathrm{Cw}=78 \%$, no additive; and, (b) Slump $=26 \mathrm{~cm}, \mathrm{Cw}=78 \%$, additive content $=2.5 \%$

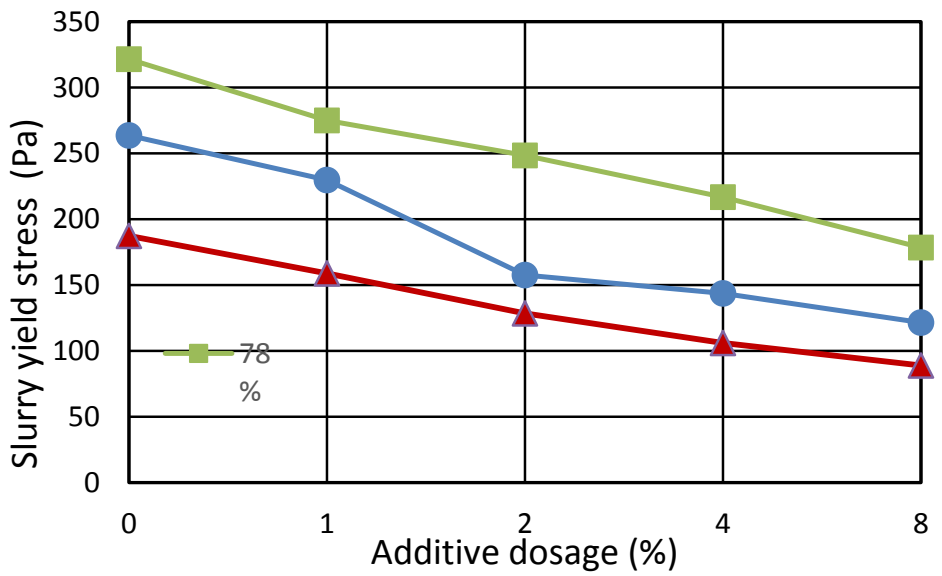

Figure 11 Yield stress curves of different pumping agent dosages

Pumping admixtures can also reduce the cement consumption and filling cost, which has obvious economic benefits. As shown in Table 2, adding pumping admixtures can reduce the cost of high-strength filling (4-5 MPa for artificial roof) by $10.34 \%$ and reduce the cost of low-strength filling (1-2 MPa for stope) by $29.96 \%$. 
The clay minerals in the unclassified tailings increase the hydration time of cement and prolong the setting time of slurry. Therefore, the proportion of each component of the pumping admixture was optimised. The retarding component was removed while the water-reducing, air-entraining and dispersing components were increased.

Table 2 Effects of adding pumping admixture on filling cost

\begin{tabular}{lllllll}
\hline Scheme & $\begin{array}{l}\text { Strength } \\
\text { (MPa) }\end{array}$ & $\begin{array}{l}\text { Concentration } \\
\text { (\%) }\end{array}$ & $\begin{array}{l}\text { Tailings-and- } \\
\text { waste/cement } \\
\text { ratio }\end{array}$ & $\begin{array}{l}\text { Tailings/waste } \\
\text { ratio }\end{array}$ & $\begin{array}{l}\text { Pumping } \\
\text { admixture } \\
\text { content (\%) }\end{array}$ & $\begin{array}{l}\text { Cost } \\
\left(\mathrm{CNY} / \mathbf{m}^{3}\right)\end{array}$ \\
\hline \multirow{2}{*}{ No additive } & $4-5$ & 73 & $4: 1$ & $5: 1$ & 0 & 135.4 \\
& $1-2$ & 73 & $8: 1$ & $5: 1$ & 0 & 82.1 \\
Additive & $4-5$ & 78 & $6: 1$ & $4: 1$ & 2 & 121.4 \\
& $1-2$ & 78 & $16: 1$ & $3: 1$ & 1.2 & 57.5 \\
\hline
\end{tabular}

A $15 \mathrm{MPa}$ plunger pump guarantees smooth transportation of high-mud content paste slurry. As Table 3 shows, the friction resistance of the whole filling line is $17.58 \mathrm{MPa}$. The vertical filling hole can also provide gravitational potential energy of $6.78 \mathrm{MPa}$ which can offset some of the on-way resistance. Therefore, the required pump pressure was $10.8 \mathrm{MPa}$. Based on this, the $15 \mathrm{MPa}$ plunger pump was selected to match this filling system. Figure 12 shows the monitoring of pump pressure at $76-78 \%$ paste slurry in $60-90 \mathrm{~m}^{3} / \mathrm{hr}$ flow rates.

Table 3 Friction resistance calculation table

\begin{tabular}{llll}
\hline Route & Layout & Length $(\mathbf{m})$ & Resistance $(\mathrm{MPa})$ \\
\hline Cemented paste backfill plant - surface filling hole & Declining & 521 & 2.64 \\
Vertical filling hole & Vertical & 364 & 2.28 \\
Horizontal filling hole & Horizontal & 320 & 2.36 \\
Horizontal filling hole -\#2 orebody & Horizontal & 1,394 & 10.3 \\
Total & & 2,599 & 17.58 \\
\hline
\end{tabular}

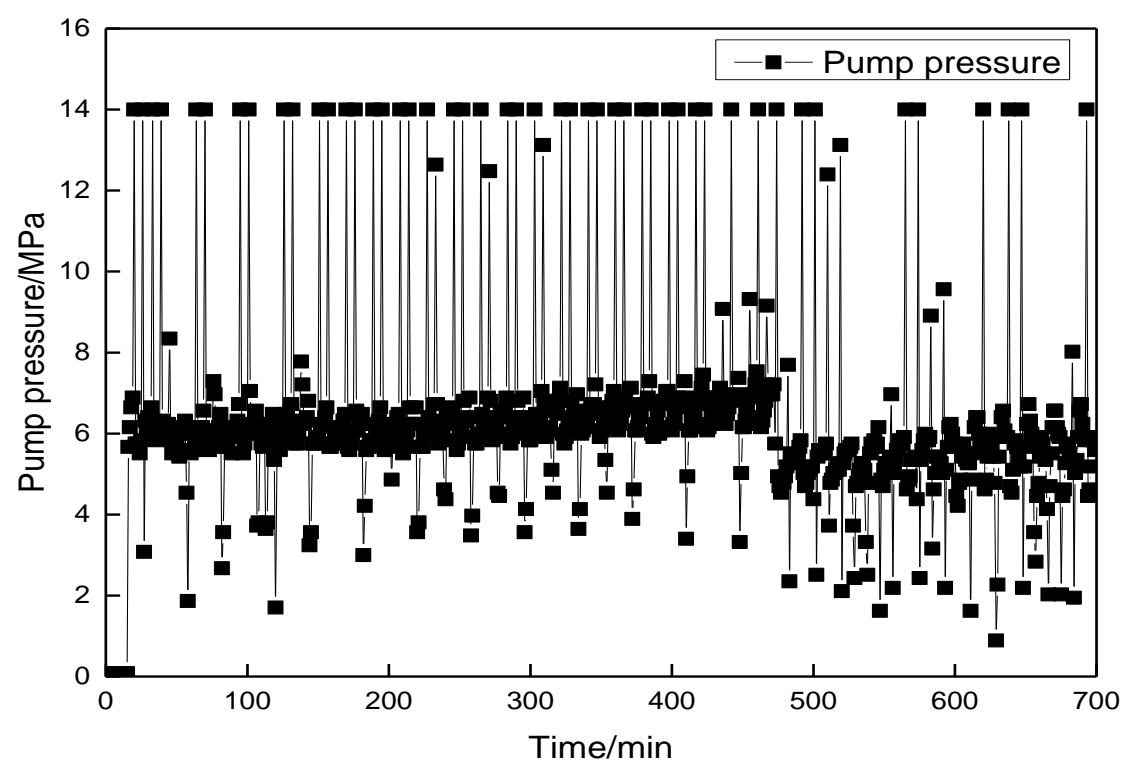

Figure 12 Pump pressure of $76-78 \%$ paste slurry under the flow of $60-90 \mathrm{~m}^{3} / \mathrm{hr}$ 


\section{$4 \quad$ Strength control of clay-rich full plant tailings paste}

The cement of clay-rich paste with high viscosity has poor dispersion and can easily form agglomeration, which leads to low, non-uniform filling strength. The clay-rich paste backfill also faces some other problems such as a long setting time and a slow strength-gain rate. Increasing the fill concentration and unit consumption of cement is not the best way to solve these problems. It will create challenges with slurry transport and increase the filling cost. Therefore, the coarse aggregate was added and the paste mixing mode was optimised to improve the compressive strength of the filling body.

The filling strength is strongly influenced by the particle gradation of the coarse aggregate. The results of the experiment show that adding well-graded coarse aggregate with a particle size of 0 to $10 \mathrm{~mm}$ was the most cost-effective method, and the seven day strength of the fill increased by eight times. Meanwhile, a segregation resistance formula was developed to prevent segregation of coarse aggregate in slurry (Saak et al. 2001).

$$
f=\frac{3 \pi C \tau_{s}}{2\left(2 \rho_{s}-\rho_{m}\right) g d} \geq 1
$$

where:

$$
\begin{aligned}
f= & \text { segregation resistance coefficient. } \\
\tau_{s}= & \text { dynamic yield stress of paste slurry }(\mathrm{Pa}) . \\
C= & \text { shear resistance coefficient }- \text { value of } 1 \text { for smooth spherical particles and } 1.2-2 \text { for } \\
& \text { non-spherical particles. } \\
d= & \text { diameter of Gobi aggregate, equivalent diameter de }=(6 \mathrm{~V} / \pi) 1 / 3 \text { for non-spherical particles }(\mathrm{m}) .
\end{aligned}
$$

In addition, automatic control was adopted for the entire process of mixing. Mixing time can be extended by maintaining a high liquid level and forming an enclosure motion of slurry (Figure 13). Therefore, cement and full plant tailings can be mixed thoroughly to improve the homogeneity of paste slurry (Beitzel et al. 2003; Doucet et al. 2008). As shown in Figure 14, the 28 day strength of the fill increased by $39.9 \%$ after the optimisation of the mixing mode.

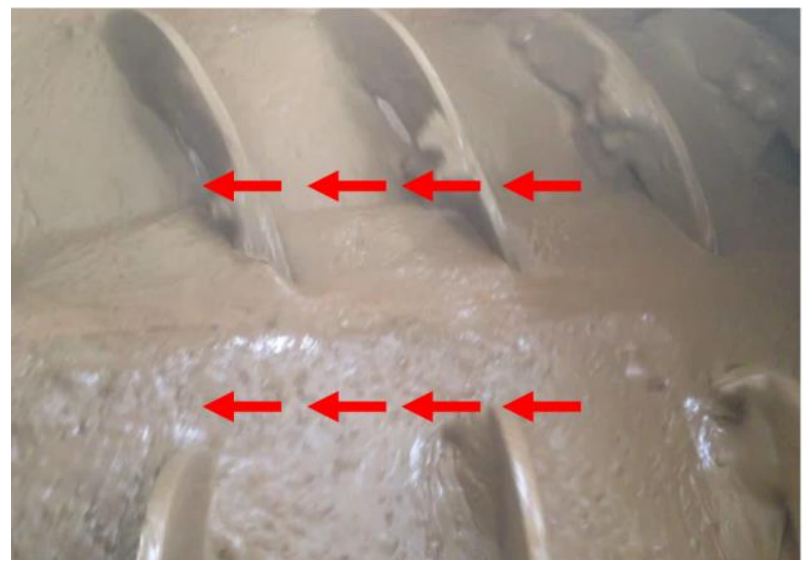

(a)

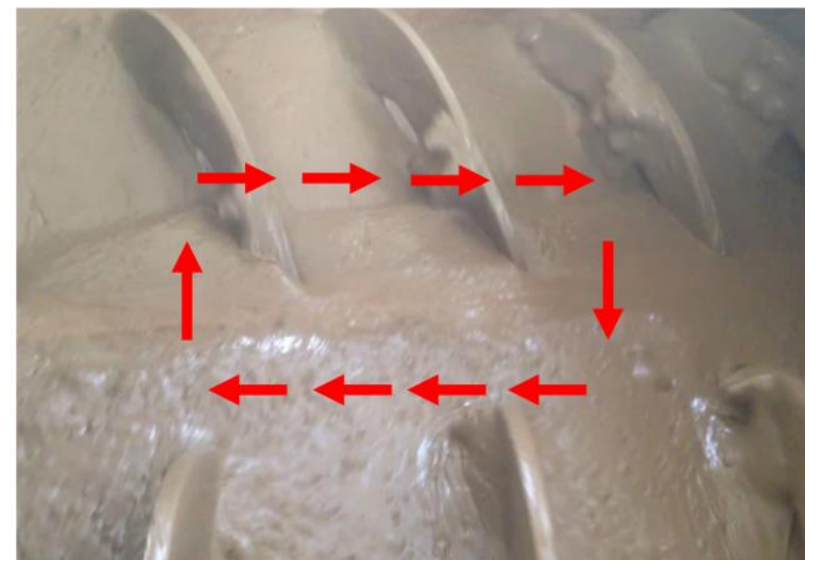

(b)

Figure 13 Optimisation of mixing mode; (a) Parallel motion; and, (b) Enclosure motion 


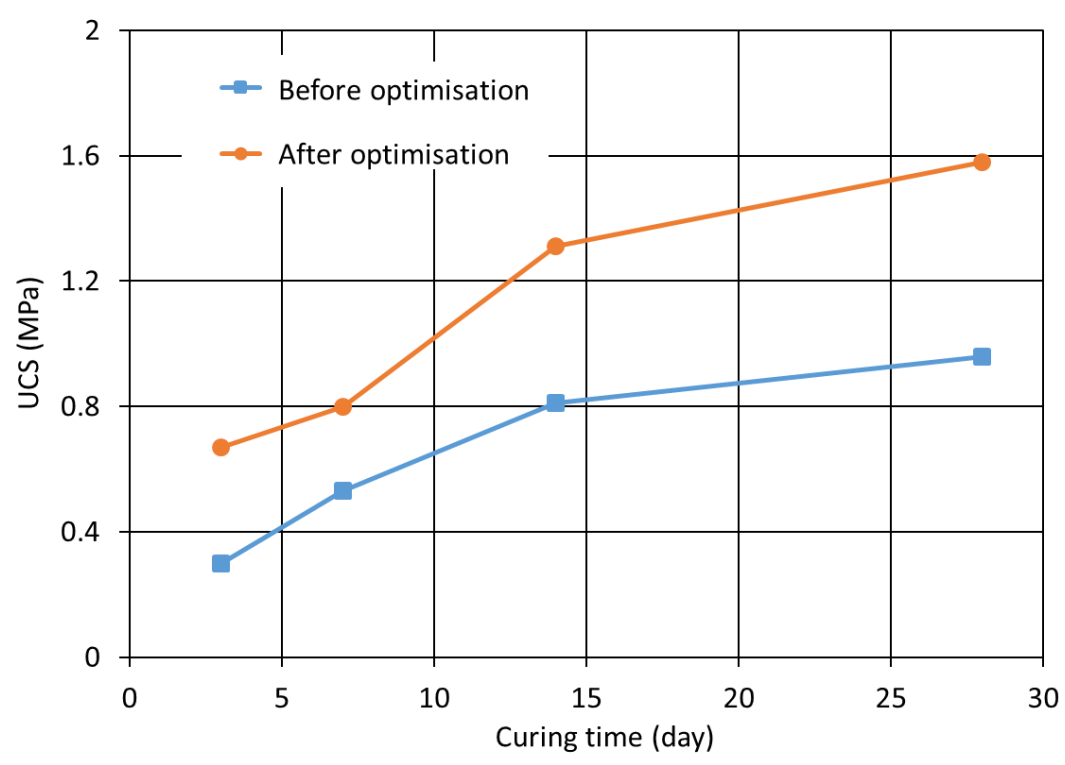

Figure 14 Strength curve of the filling body before and after optimisation of the mixing mode

\section{Conclusion}

This project has overcome several difficulties, including thickening of clay-rich full plant tailings and transportation, and low strength of clay-rich paste with high viscosity. Clay-rich full plant tailings paste backfill technology, which could be applied in the ore and rock that are easy to slime in the presence of water, was developed for the first time.

- In thickening, selecting the most appropriate flocculant and adding the secondary dilution system can help improve the flocculation effect of clay-rich unclassified tailings. Thus, an underflow concentration of $70-72 \%$ can be achieved.

- Adding pumping admixture can reduce the yield stress of high-concentration slurry by $45 \%$ and decrease the plastic viscosity by two times. The paste slurry was transported over a distance of $2.6 \mathrm{~km}$ by a high-pressure (15 MPa) plunger pump. Based on this, long-distance transportation of clay-rich paste with high viscosity can be achieved.

- Gobi aggregates were added to optimise slurry gradation. Paste concentration increased from 75 to $80 \%$ and the strength of the paste backfill body increased by five times.

\section{Acknowledgement}

The authors express their gratitude to Jiashi Tonghui Copper Mine Co., Ltd for allowing this case study to be published. This work is financially supported by the National Natural Science Foundation of China (51474034) and University of Science and Technology Beijing.

\section{References}

Beitzel, H, Charonnat, Y \& Beitzel, M 2003, 'Assessment and classification of performance mixers', Materials and Structures, vol. 36, no. 258, pp. 250-264.

Doucet, J, Bertrand, F \& Chaouki, J 2008, 'A measure of mixing from Lagrangian tracking and its application to granular and fluid flow systems', Chemical Engineering Research and Design, vol. 86, no. 12, pp. 1313-1321.

Saak, AW, Jennings, HM \& Shah, SP 2001, 'New methodology for designing self-compacting concrete', ACl Materials Journal, vol. 98, no. 6, pp. 429-439. 